dead mice and birds are always found, and are common in other regions as well. The well-known Grotto del Cano, near Naples, is the most familiar example of such accumulations of carbonicacid gas ; and visitors are frequently entertained by the asphyxiation of a poor dog, while the guide, whose head rises above the gas, is not affected by it. Death Gulch is, however, without a peer as a natural bear-trap, and may well be added to the list of the wonders of the Yellowstone Park. WALTER H. WEED.

U. S. Geol. Surv., Washington, Jan. 3o.

A New Method for the Microscopical Examination of Water.

IN making microscopical ${ }^{1}$ examinations of potable waters, it is entirely impracticable, on account of their relative purity, to proceed directly. Repeated examinations of random samples might yield absolutely nothing, although filtration of a few cubic centimetres through a fine cloth might show that in the same water there were abundant microscopic forms.

The importance of being able to ascertain the presence of these microscopic organisms, and to determine their number and species in any given sample of water, is self-evident. It is important, not only from a purely scientific, but also from a sanitary, point of view, to know precisely what is contained in drinking-water. Again: large manufacturing interests are dependent upon the purity of the water supplied to them through filters or otherwise, while many large towns depend upon the efficiency of filters for the purity of their water-supply. A microscopical examination of the water before and after filtration shows very clearly the actual work which the filter accomplishes, in a way that it is impossible for chemical analyses to do. From a scientific and sanitary point of view, microscopical examinations are accordingly of great value both as a means for the study of the organisms themselves, and of the influences of changes in the water upon their growth, life, and death, as well as the counter effects produced upon the water by them. For making such examinations there have been hitherto, so far as I know, but two methods employed. One of these is that proposed by Dr. J. D. McDonald in his "Guide to Microscopical Examination of Water" (J. \& A. Churchill, London, i 883). In this method the sample to be examined is put into a tall glass cylinder, at the bottom of which is a watch-glass suspended by a platinum wire. This is allowed to stand for forty-eight hours, in order that the matters held in suspension may settle into the watch-glass at the bottom. The upper water is then siphoned off, and the contents of the watch-glass examined under the microscope.

The other method, the origin of which $I$ do not know, is used at present by the Massachusetts State Board of Health. In this method a given quantity of water is passed through a fine linen or cotton cloth tied to the lower end of a funnel. After the water has passed through it, the cloth is removed, and cautiously reversed over the end of a glass tube, the numerous objects which have been caught upon the cloth being now upon the outside. A slide is then placed under the cloth, and a puff of air blown through the tube. The moisture contained in the cloth collects in a drop, which falls upon the slide, carrying with it theoretically the materials filtered out of the water. The slide is then examined under the microscope, and the organisms obtained counted. Both these methods are open to very serious objections, and are so crude that no fair estimates of the number of organisms contained in a given sample of water can be formed. In the case of the first method, I have found that by no means all of the microscopic organisms settle to the bottom, even when the water is left standing a much longer time than forty-eight hours, as there are many which have about the same specific gravity as water, and consequently do not settle. This source of error becomes greater in proportion as the water to be examined becomes purer. In the case of ordinary drinking-water, the sediment is very inconsiderable, although there are large numbers of organisms held in suspension. Under ordinary circumstances, water left standing in this way gives an excellent opportunity for the organisms present to increase. Especially is this the case with filtered water, where the increase is surprisingly rapid. From this it is plain that the sediment in the watchglass does not represent what was originally in the water, but only

1 It is convenient to designate by "microscopic" all forms of life visible oniy by means of the microscope, exclusive of the bacteria. a small part of that amount plus a part of the increase which has since taken place. In the second method, if the cloth be examined microscopically after presumably all the microscopic organisms have been removed, it will often be found that a very large number are stuck in the meshes of the cloth.

For these two methods I have substituted one which, although far from perfect, gives much better results. I have now been using it for four months in making microscopical examinations of water for the city of Boston.

The new method is as follows. A known quantity of water (I have found roo cubic centimetres a convenient unit) is put into a funnel in the tube of which is half an inch in depth of sand (24 to 30 grains to the inch). The sand is held in place by a stop made of a roll of brass wire gauze, which gives free passage to the water, while it holds the sand in place. Through this the water is filtered, the sand holding back the microscopic forms. The experiments which I have tried, to test whether all the organisms are removed or not, have proven conclusively the efficiency of the sand in holding back all the microscopic organisms in the water. After all the water has passed through, the stop is removed, and one cubic centimetre of distilled water (the water which has just been filtered will answer as well) is thrown into the funnel by means of a pipette. This washes the sides of the funnel, and carries the sand with it down into a watch-glass which is held unclerneath to receive it. On falling into the watch-glass, the grains of sand separate and sink to the bottom, leaving the lighter organisms which have been caught between them mostly suspended in the water. By stirring this wash-water a more even distribution of the organisms is obtained, and, if any have been carried to the bottom by the falling sand, they are liberated; so that if the wash-water be poured off, and the sand examined under the microscope, it will be found that there are no more organisms among it than might be expected. Some of the water standing above the sand is immediately transferred to a slide containing a chamber the capacity of which is one cubic millimetre. All the microscopic organisms contained in this chamber are then counted under the microscope, and from the result the total number of organisms in the original sample is computed. I have found this cubic millimetre surprisingly representative of the whole mass of the wash-water, as far as the numbers go, although, as would naturally be expected, the species vary largely in different samples.

This method, as the first which can fairly be called quantitative, opens up a new field, having wide and practical applications. It is to be hoped that microscopical examinations may hereafter take their proper place alongside of bacteriological and chemical analyses, to which they must form important adjuncts.

Mass. Inst. Technol., Boston, Feb. r.

A. L. KEAN.

\section{Triple Births in the Human Race.}

I waS much interested in the note published in Science of Feb. 8, upon triple births in the human race, and I beg to direct your attention to a curious case to be found among the records of Middleboro [Mass.?], in which triple births occurred in two successive generations of the same family.

Elisha Vaughan married Joanna Morton, daughter of John Morton of Middleboro.

Children of Elisha and Joanna Vaughan.

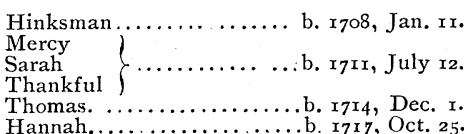

Children of Hinksman and Desire Vaughan.

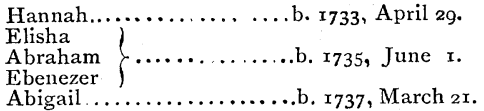

The town and church records in Middleboro comment upon the curious reversal of the sexes in the two generations.

Washington, Feb. Ix alexander Graham Bell. 